Citation: Hirt C., Schmitz M., Feldmann-Westendorff U., Wübbena G., Jahn C.-H., and Seeber G. (2010) Mutual validation of GNSS height measurements from high-precision geometric-astronomical levelling, GPS Solutions, Volume 15, Issue 2 (2011), Page 149-159. DOI 10.1007/s10291-010-0179-3.

\title{
Mutual validation of GNSS height measurements and high-precision geometric-astronomical levelling
}

\author{
Christian Hirt \\ Martin Schmitz \\ Uwe Feldmann-Westendorff \\ Gerhard Wübbena \\ Cord-Hinrich Jahn \\ Günter Seeber \\ C. Hirt \\ Western Australian Centre for Geodesy \\ Curtin University of Technology \\ GPO Box U 1987 \\ Perth, WA 6845, Australia \\ Chris.Hirt@web.de \\ c.hirt@curtin.edu.au \\ M. Schmitz, G. Wübbena \\ Geo++, Gesellschaft für satellitengestützte geodätische und navigatorische Technologien mbH, \\ Garbsen, Germany \\ U. Feldmann-Westendorff, C.-H. Jahn \\ Landesvermessung und Geobasisinformation Niedersachsen (State Survey Agency of Lower \\ Saxony), Hannover, Germany \\ G. Seeber \\ Institut für Erdmessung, Universität Hannover, Germany.
}

Received: date / Accepted: date 


\begin{abstract}
The method of geometric-astronomical levelling is presented as a suited technique for the validation of GNSS (Global Navigation Satellite System) heights. In geometric-astronomical leveling, the ellipsoidal height differences are obtained by combining conventional spirit leveling and astronomical leveling. Astronomical leveling with recently developed digital zenith camera systems is capable of providing the geometry of equipotential surfaces of the gravity field accurate to a few $0.1 \mathrm{~mm}$ per $\mathrm{km}$. This is comparable to the accuracy of spirit leveling. Consequently, geometric-astronomical leveling yields accurate ellipsoidal height differences that may serve as an independent check on GNSS height measurements at local scales. A test was performed in a local geodetic network near Hanover. GPS observations were simultaneously carried out at five stations over a time span of 48 hours and processed considering state-of-theart techniques and sophisticated new approaches to reduce station-dependent errors. The comparison of GPS height differences with those from geometric-astronomical leveling shows a promising agreement of some millimeters. The experiment indicates the currently achievable accuracy level of GPS height measurements and demonstrates the practical applicability of the proposed approach for the validation of GNSS height measurements as well as the evaluation of GNSS height processing strategies.
\end{abstract}

\title{
Keywords
}

GNSS heighting, GNSS modeling, geometric-astronomical levelling, vertical deflection, digital zenith camera system (DZCS)

\section{Introduction}

The combined use of GNSS (Global Navigation Satellite System) height determination and geoid models, known as GNSS-leveling, has become an economic technique for the determination of physical heights (Meyer et al. 2006a; Feldmann-Westendorff and Jahn 2006; Featherstone 2008; Feldmann-Westendorff 2009). A better understanding of especially station dependent errors like antenna phase variations and near-field multipath significantly improved GNSS observation and modeling (Schmitz and Wübbena 2007; Wübbena et al. 2000; Wübbena et al. 2003; Wübbena et al. 2006). In regions with accurate geoid information available, GNSS-leveling may substitute spirit leveling over large distances. In practice, an accuracy level of $1 \mathrm{~cm}$ and better for GNSSbased physical heights is often reached (Feldmann-Westendorff and Jahn 2006). Further improvements towards the millimeter level, however, not only require considerable efforts in geoid modeling and GNSS height determination, but also suitable validation techniques.

Validation of GNSS height measurements basically requires independent ellipsoidal heights or ellipsoidal height differences at the same or even a higher level of accuracy than attained with 
GNSS. Independent ellipsoidal comparison data is either obtained by means of geometricastronomical leveling (Torge 2001, p. 232) or trigonometric leveling, using mutual and simultaneous zenith angle measurements (Torge 2001, p. 252). The use of the first approach for GNSS height validation is the topic of the present paper.

It is well-known that heights or height differences from geometric leveling, aka spirit leveling, are not compatible with ellipsoidal heights from GNSS observations. This is due to the fact that leveled heights refer to the equipotential (level) surfaces of the Earth gravity field whereas GNSS heights are related to a reference ellipsoid, having a pure geometrical meaning (Meyer et al. 2006b). Geometric-astronomical leveling provides a solution to this problem. The concept of this technique is to correct spirit-leveled height differences with the geoid undulations from astronomical leveling, thus yielding ellipsoidal height differences. Alternatively, a sufficiently accurate geoid/quasigeoid model may be used instead of astronomical leveling.

The idea behind geometric-astronomical leveling (Sec. 2) was first described by Helmert (1884), who suggested to correct for the impact of the gravity field on leveled heights by means of vertical deflections, yielding purely geometrical heights. A further treatise of the theory of geometric-astronomical leveling was later presented by Molodenski et al. (1962). Over several decades, geometric-astronomical leveling represented an alternative method to trigonometric leveling for ellipsoidal height determination. The method was applied in local and regional threedimensional geodetic networks, mostly at the centimeter to decimeter accuracy level (Heitz 1973; Torge et al. 1975; Torge 1977; Torge and Wenzel 1978; Bäumker 1984).

With the evolution of satellite-positioning, GNSS became the standard of ellipsoidal heighting, having several advantages over geometric-astronomical leveling, e.g., in terms of accuracy and efficiency. Early test results of comparisons between GPS (Global Positinging System) ellipsoidal heights, spirit-levelled heights and geoid undulations from vertical deflections were reported by Ruland and Leick (1985). A later variant of geometric-astronomical leveling was the determination of vertical deflections based on the combination of spirit leveling and the GPS measurement of ellipsoidal height differences (Soler et al. 1989, Mogilevsky and Melzer 1994, Tse and Baki Iz 2006).

In recent years, advancements in automated observation of vertical deflections using digital zenith camera systems (DZCS) considerably improved the performance of astronomical levelling (Hirt et al. 2010). DZCS astronomical leveling was successfully used at the millimeter level for the local validation of gravimetric quasigeoid models in Germany (Hirt et al. 2007; Hirt et al. 2008). As a direct consequence of these developments, geometric-astronomical leveling may be used nowadays to provide ellipsoidal height differences at the millimeter level and even better over short distances up to several km (Sec. 3). This makes geometric-astronomical leveling a suited validation technique for satellite-based height determination.

In order to test geometric-astronomical leveling for evaluation of GNSS heighting, accurate GPS measurements were performed in a local test area in Northern Germany where a set of DZCS vertical deflections is available. For the GPS measurements and processing, state-of-the-art knowledge and techniques were applied (Sec. 4). Comparisons among ellipsoidal height 
differences from GPS and geometric-astronomical leveling (Sec. 5) demonstrate that geometricastronomical leveling is a method which allows validation of GNSS-based heighting and evaluation of modern GNSS height processing strategies.

\section{Methodology}

The well-known geometric leveling yields a number of height increments $\Delta n$ along a connecting path between two stations $\mathrm{A}$ and $\mathrm{B}$. The sum of the leveled, raw height increments is an approximation of the orthometric height difference $\Delta H_{A B}$ between both stations:

$$
\Delta H_{A B} \approx \sum \Delta n \text {. }
$$

The same approximate relation holds for normal height differences which are not further treated here. In a rigorous treatment, the orthometric height difference $\Delta H_{A B}$ is obtained by integration of infinitely small height increments $\delta n$ and consideration of the orthometric (height) correction $E_{A B}^{O}$ (Heiskanen and Moritz 1967, p. 160 ff):

$$
\Delta H_{A B}=\int_{A}^{B} \delta n+E_{A B}^{O}=\Delta H_{A B}^{*}+E_{A B}^{O}
$$

with $\Delta H_{A B}^{*}$ representing the uncorrected spirit leveled height difference.

The orthometric correction $E_{A B}^{O}$ is given by:

$$
E_{A B}^{O}=\int_{A}^{B} \frac{g-\gamma_{0}^{45}}{\gamma_{0}^{45}} \delta n+\frac{\bar{g}_{A}-\gamma_{0}^{45}}{\gamma_{0}^{45}} H_{A}-\frac{\bar{g}_{B}-\gamma_{0}^{45}}{\gamma_{0}^{45}} H_{B}
$$

where $g$ is the surface gravity observed along the connecting path (e.g., taken from gravity databases), $\bar{g}_{A}, \bar{g}_{B}$ are mean gravity values along the plumb line of stations $\mathrm{A}$ and $\mathrm{B}, H_{A}, H_{B}$ are the respective values of the orthometric heights of station $\mathrm{A}$ and $\mathrm{B}$ (approximated values are usually sufficient) and $\gamma_{0}^{45}$ is an arbitrary constant gravity value (Heiskanen and Moritz 1967; Torge 2001).

The orthometric correction $E_{A B}^{O}$ takes into account the nonparallelism of the equipotential surfaces of the gravity field, and the curvature of the plumb line, respectively. It accounts for the fact that leveling results depend on the path chosen to connect stations A and B (Heiskanen and Moritz 1967; Meyer et al. 2006b).

The main difficulty associated with evaluation of (3) is the computation of the mean gravity values $\bar{g}_{A}, \bar{g}_{B}$ along the plumb lines at the first and last station (Torge 2001). Generally, it is not possible to observe gravity continuously along the plumb line, as required at least theoretically for the computation of the mean gravity values, which is why hypotheses on the density distribution are made (Torge 2001, p. 82; Featherstone and Kuhn 2006, p. 21). As the orthometric correction $E_{A B}^{O}$ cancels out in geometric-astronomical leveling (shown below), the computation of this variable is not further detailed here. 
In astronomical leveling, vertical deflections are integrated along a path in order to determine the difference in geoid undulation between the stations A and B (Heiskanen and Moritz 1967, p. 197; Torge 2001, p. 296) :

$$
\Delta N_{A B}=-\int_{A}^{B} \varepsilon d s-E_{A B}^{O}=\Delta N_{A B}^{*}-E_{A B}^{O}
$$

with $\varepsilon$ vertical deflection in path direction and $d s$ spacing between adjacent stations (see Figure 1). $E_{A B}^{O}$ is the orthometric correction already known from geometric leveling (3). Here and in the following sections, the quantity $\Delta N_{A B}^{*}$ denotes the astronomical leveling results without orthometric correction, and, for simplicity, is also referred to as geoidal height difference.

The vertical deflection component $\varepsilon$ represents the inclination of the equipotential surface against the ellipsoid. It is computed as a function of the North-South deflection component $\xi$, the East-West component $\eta$ and the azimuth $\alpha$ (Heiskanen and Moritz 1967, p. 197; Jekeli 1999)

$$
\begin{aligned}
& \xi=\Phi-\varphi, \\
& \eta=(\Lambda-\lambda) \cos \varphi, \\
& \varepsilon=\xi \cos \alpha+\eta \sin \alpha .
\end{aligned}
$$

Second order terms are neglected here which must be taken into account in mountainous terrain (Jekeli 1999). To date, vertical deflections $(\xi, \eta)$ can be economically observed with modern DZCS (cf. Sec. 4.2). Such systems provide the direction of the physical plumb line (astronomical latitude $\Phi$ and longitude $\Lambda$ ) as well as the ellipsoidal normal (geodetic latitude $\varphi$ and longitude $\lambda$ ), using GNSS.

GNSS-leveling uses the fundamental relation between ellipsoidal heights $h$, orthometric heights $H$ and geoid undulation $N$ :

$$
h=H+N,
$$

wherein small effects due to the curvature of the plumb line and nonparallelism of the plumb line and ellipsoid, reaching sub-millimeter order of magnitude, are neglected (Torge 2001 p. 234). For differences of heights between two stations $\mathrm{A}$ and $\mathrm{B}$, the relation reads as:

$$
\Delta h_{A B}=\Delta H_{A B}+\Delta N_{A B} .
$$

The technique of geometric-astronomical leveling combines spirit leveled height differences $\Delta H_{A B}$ (2) and geoid height differences $\Delta N_{A B}$ as obtained from astronomical leveling (4). Replacing the respective terms in (7) yields:

$$
\begin{aligned}
& \Delta h_{A B}=\int_{A}^{B} \delta n+E_{A B}^{O}-\int_{A}^{B} \varepsilon d s-E_{A B}^{O} \\
& =\int_{A}^{B} \delta n-\int_{A}^{B} \varepsilon d s .
\end{aligned}
$$


The orthometric correction $E_{A B}^{O}$ cancels out when both integrals are formed over the same path between A and B (cf. Figure 1). This is the main conceptual advantage of geometric astronomical leveling. Using the same path for the spirit leveling and astronomical leveling is beneficial in level regions and particularly in mountainous terrain, so as to exclude any impact of $E_{A B}^{O}$ computations on the ellipsoidal height differences. In view of GNSS height validation, a drawback of geometric-astronomical leveling is the fact that solely ellipsoidal height differences are obtained, and not (absolute) ellipsoidal heights.

Note that (8) implicitly assumes axes parallelism of the reference ellipsoid (Geodetic Reference System GRS 80) and the geocentric coordinate system (International Terrestrial Reference System ITRS) the vertical deflections refer to. It may be assumed that this condition is sufficiently fulfilled (Torge 2001). Of course, (8) also holds if normal heights and quasigeoid undulations are introduced instead of orthometric heights and geoid undulations (then the normal correction would cancel out instead of the orthometric correction).

The practical application of geometric-astronomical leveling requires a discretization of the two path integrals in (8). The first term is usually evaluated by the sum of spirit-leveled height increments $\Delta n$. The substitution of the second integral demands a dense set of vertical deflections at the Earth surface, representing the geometry of the equipotential surfaces properly. Then, a linear interpolation between vertical deflections of adjacent stations $i, i+1$ can be performed without loss in accuracy:

$$
\varepsilon=\frac{\varepsilon_{i}+\varepsilon_{i+1}}{2}
$$

The basic equation of geometric-astronomical leveling now reads:

$$
\Delta h_{A B}=\Delta H_{A B}^{*}+\Delta N_{A B}^{*}
$$

with the leveled height difference

$$
\Delta H_{A B}^{*}=\sum_{A}^{B} \Delta n_{i}
$$

and the geoidal height difference

$$
\Delta N_{A B}^{*}=-\sum_{A}^{B} \frac{\varepsilon_{i}+\varepsilon_{i+1}}{2} d s .
$$

In level terrain, a station spacing of some $100 \mathrm{~m}$ is usually sufficient for evaluation of (9), whereas in hilly or mountainous regions a much denser spacing (shorter than $100 \mathrm{~m}$ ) may be required for a reliable interpolation. This is due to the fact that the shape of the equipotential surfaces (and hence their inclination, represented by vertical deflections) is strongly correlated with the topography (Torge 2001, p. 260 and p. 290). If vertical deflection observations are available at larger spacings, a dense set of surface vertical deflections can be precisely interpolated using high-resolution digital terrain model (DTM) data (e.g., Hirt and Flury 2008). 


\section{Theoretical accuracy assessment}

The accuracy $\sigma_{\Delta h}$ of the ellipsoidal height differences $\Delta h$, as derived from geometricastronomical leveling (10)-(12), is a function of the accuracy of spirit-leveled height differences $\Delta H^{*}$ and astronomically derived geoidal height differences $\Delta N^{*}$ :

$$
\sigma_{\Delta h}=\sqrt{\sigma_{\Delta H^{*}}^{2}+\sigma_{\Delta N^{*}}^{2}} \text {. }
$$

For precision spirit-leveling, often a standard deviation $\sigma_{\Delta H^{*}}$ of about $0.3-0.4 \mathrm{~mm} / \sqrt{\mathrm{km}}$ is assumed. The error theory of spirit-leveling is well documented in the geodetic literature (Vaníček et al. 1980, Bomford 1980; Torge 2001) and will not be repeated here. However, some remarks should be made on the error propagation in astronomical leveling.

The accuracy $\sigma_{\Delta N^{*}}$ of the geoidal height differences can be estimated applying the propagation law for random errors. Assuming uncorrelated errors in the vertical deflections yields approximately (Hirt 2009):

$$
\begin{aligned}
& \sigma_{\Delta N^{*}}[\mathrm{~mm}] \approx 4.8 \cdot d s \cdot \sqrt{n-1} \cdot \sigma_{\varepsilon} \\
& =4.8 \cdot \frac{S[\mathrm{~km}]}{\sqrt{n-1}} \cdot \sigma_{\varepsilon}
\end{aligned}
$$

where $\sigma_{\varepsilon}$ is the accuracy of the deflections ["], $d s$ average station spacing [km], $S$ length of the traverse $[\mathrm{km}]$ and $n$ number of stations. For instance, introducing an observational accuracy $\sigma_{\varepsilon}$ of about $0.1^{\prime \prime}$ and a spacing $d s$ of $50 \mathrm{~m}$, a standard deviation $\sigma_{\Delta N^{*}}$ of $0.1 \mathrm{~mm}$ is obtained for the determination of geoidal height differences over a distance $S$ of $1 \mathrm{~km}$ (station count $n=21$ ). Even for larger station spacings (e.g. $d s=200 \mathrm{~m}$ ), accuracies at the level of a few $0.1 \mathrm{~mm}$ over $1 \mathrm{~km}$ are attainable. Concluding, astronomical leveling is capable of attaining a level of accuracy similar to that of spirit leveling.

As with all leveling techniques, it is mandatory to analyze the impact of systematic errors due to their unfavorable propagation characteristics. A systematic error in the vertical deflections of 1 " translates into geoidal height differences by $4.8 \mathrm{~mm}$ over $1 \mathrm{~km}$ traverse length (rule of thumb). Hence, a generalized expression for the computation of systematic errors in astronomical leveling reads:

$$
\delta \Delta N^{*}[\mathrm{~mm}] \approx 4.8 \cdot S[\mathrm{~km}] \cdot \delta \varepsilon
$$

with $\delta \varepsilon$ systematic vertical deflection error ["] and $S$ traverse length. For example, an assumed systematic error of about 0.05 " causes a bias of about $0.25 \mathrm{~mm}(0.5 \mathrm{~mm})$ over a traverse length of $1 \mathrm{~km}(2 \mathrm{~km})$. In particular, refraction anomalies are considered to be a potential source for systematic errors of vertical deflections (e.g., Hirt 2006). Consequently, systematic errors may accumulate over longer traverses and have to be treated with some care. Of course, this also holds for geometric leveling.

On condition that systematic error sources of the two leveling techniques are being kept 
reasonably small, geometric-astronomical leveling is expected to provide ellipsoidal height differences $\delta h$ accurate to about $0.5-0.6 \mathrm{~mm} / \sqrt{\mathrm{km}}$ at least over short distances. This allows validation of GNSS height measurements at local scales.

\section{Testing geometric-astronomical leveling}

In order to test geometric-astronomical leveling for the validation of GNSS ellipsoidal heights, a comprehensive field experiment was carried out in the test area "Steinhude" near Hanover. This area was selected because a dense set of astrogeodetic vertical deflections was available from DZCS observations (Hirt and Seeber 2007; Hirt 2009). The test area is located in flat terrain at a height of about $50 \mathrm{~m}$ above mean sea level. Along a $7 \mathrm{~km}$ long traverse, all measurement stations were aligned to the course of the "Mittellandkanal", a canal crossing the test area approximately in East-West-direction (cf. Figure 2). A salt dome named "Steinhuder-Meer-Linie" is located in the middle of the test area. This subterranean density anomaly influences locally the shape of the gravity field. At five benchmarks, arranged in the course of the vertical deflection stations (cf. Figure 2), GPS observations and spirit leveled height differences were observed at almost the same epoch in spring 2006.

\subsection{Geometric leveling}

Digital precision leveling equipment (Leica NA3003, Leica DNA03) was applied by the state survey agency of Lower Saxony for double-run leveling in order to determine the height differences $\Delta H_{i j}^{*}$ (the indices $i, j$ denote adjacent pairs of benchmarks $\mathrm{AB}, \mathrm{BC}, \mathrm{CD}$ and $\mathrm{DE}$ ). The leveling equipment is specified for first-order vertical control. The theoretical accuracy for leveled height differences is estimated to be about $0.3-0.4 \mathrm{~mm} / \sqrt{\mathrm{km}}$ for double-run leveling. Precision leveling was performed by taking all generally accepted leveling rules into consideration (see Vaníček et al. 1980). Because the leveling was carried out along larger loops and not along the shortest possible connection between adjacent benchmarks (Table 1), the accuracy of height differences $\Delta H_{i j}^{*}$ varies between 1-2 mm (estimates obtained from a least squares adjustment), cf. Table 1 . This is lower than theoretically possible for direct leveling runs between adjacent benchmarks. A later repetition of the leveling was not possible because the test area is subject to vertical displacements originating from mining.

\subsection{Vertical deflections and astronomical leveling}

The DZCS TZK2-D (Transportable Zenitkamera 2-Digitalsystem), developed and operated at University of Hanover, was used for the observation of vertical deflections. This state-of-the-art astrogeodetic measuring system (Figure 3) consists of a digital telescope for automated star observation, yielding astronomical coordinates $(\Phi, \Lambda)$ as required in (5). The geodetic 
coordinates $(\varphi, \lambda)$ of the camera are derived from differential GPS observations at the centimeter accuracy level (this equates to about $0.001^{\prime \prime}$ ). The error budget of the DZCS vertical deflection measurement is dominated by the uncertainties of the astronomical coordinates. Based on a standard 20 min DZCS observation, astronomical coordinates $(\Phi, \Lambda)$ and, hence, vertical deflections $(\xi, \eta)$ are usually obtained accurate to about $0.08^{\prime \prime}-0.10^{\prime \prime}$ (Hirt and Seeber 2008). For details on the technical realization of DZCS and field routine see Hirt et al. (2010).

In our test area, a very dense station spacing of about $50 \mathrm{~m}$ between adjacent stations was realized. This was done so as to study the Earth's gravity field characteristics at very short scales (Hirt and Seeber 2007; Hirt 2009). During a first measurement campaign in spring 2005, the TZK2-D was used for collecting vertical deflections at about 140 stations along the traverse (Figure 2). In autumn 2005, vertical deflections were observed a second time at all stations. Both vertical deflection data sets are shown in Figure 3 together with the five benchmarks A-E. Based on the residuals between these two data sets, the standard deviation was found to be about $0.09^{\prime \prime}$ for both vertical deflection components $(\xi, \eta)$.

For the transformation of vertical deflections $(\xi, \eta)$ to geoidal height differences $\Delta N^{*}$, a linear interpolation was applied (12). DTM data was not used for the interpolation of vertical deflections because of the fairly level terrain in our test area and the very short distances between adjacent DZCS observations.

To empirically assess the accuracy of the $\Delta N^{*}$ values, the geoidal height difference (12) was computed separately both with the vertical deflection data collected during spring 2005 and the data collected in autumn 2005. The differences obtained from both computations indicate that sub-millimeter-accuracy was attained for the geoidal height differences $\Delta N^{*}$ between adjacent benchmarks (Table 2). The magnitude of the residuals between benchmarks AB, BC and CD are in agreement with the error propagation law (14). A significantly larger difference of $-0.7 \mathrm{~mm}$ was found between benchmarks $\mathrm{C}$ and $\mathrm{D}$, indicating a systematic error. A possible cause could be a season-dependent systematic refraction effect, originating from horizontal temperature gradients between the canal and the surrounding area (Hirt 2009). This effect is visible in the deflection component $\eta$ between benchmarks $\mathrm{C}$ and $\mathrm{D}$, where a small systematic difference between the two campaigns is present (Figure 4). The definite computation of $\Delta N^{*}$ values for the determination of ellipsoidal height differences $\Delta h$ is based on the mean of both vertical deflection data sets with the result that refractional influences (in particular those between benchmarks $\mathrm{C}$ and D) are reduced.

\subsection{GNSS observations and modeling}

The main limiting factors for precise GNSS height determination are station and troposphere dependent impacts on the received satellite signals. Therefore certain efforts were placed on controlling and modeling these parameters considering state-of-the-art techniques and some new 
concepts.

Individual GNSS error components are either corrected, or modeled, or reduced/eliminated through the observation setup (Seeber 2003). The tropospheric delay of the signals is corrected at a first step by a standardized troposphere model and is further improved in the processing using the actual GNSS data. For the station dependent errors, however, the impact has to be considered already in the field setup of the GNSS stations and optimized corrections have to be applied in the processing. First of all, the station dependent errors are discussed, which are

- antenna phase center offset and variations (PCV),

- near-field multipath action on the antenna,

- far-field multipath from the station environment.

The PCV are determined individually for all receiving antennas using the Geo++ Absolute Field Calibration with a robot (Wübbena et al. 2000). The precise PCV corrections can be applied in the processing. General analysis (Elosegui et al. 1995) and detailed investigations of the interaction of GNSS antennas with the close vicinity using the robot calibration system (Wübbena et al. 2003; Wübbena et al. 2006) revealed, that PCV corrections are superimposed by site-dependent near-by multipath effects. To overcome these effects, multipath is separated into near-field and far-field effects, which do have completely different characteristics and must therefore be considered differently in precise GNSS applications.

Far-field multipath is the part generally known by the term multipath with a high frequency of phase variations and bounded by a quarter of the wavelength. Far-field multipath is eliminated in static applications through averaging over longer observation times (few minutes up to 20 min depending on the distance of reflectors). Over time, far-field multipath has a zero mean.

Different to this, near-field multipath in the close vicinity of the GNSS antenna has very long periods of several hours caused by reflexion, bending and imaging due to the devices used for antenna mounting (tribrach, tripod, stand-offs etc.). The effect on the phase does not have a zero mean, hence, it does not average out and it is a bias affecting especially the height component. The bias is changing with time, duration and location due to the changing satellite constellation, but also with the actual antenna setup in the field (Wübbena et al. 2006; Dilssner et al. 2008).

To account for the near-field effects acting on the GNSS measurements, a controlled setup of all stations is used for field measurements. The setup of antenna, tribrach and top part of the tripod were calibrated with the Geo++ robot calibration system, which is capable of determining the sum of PCV and near-field impact while using a representative setup during calibration. The quality of the so-called near-field calibration $(\mathrm{PCV}+\mathrm{NF})$ depends on the degree of resemblance of the mock-up and the final station setup.

Therefore, a certain orientation, tribrach height, and inclination of tripod legs were defined and later reproduced best in the field, which forced the centering and leveling mainly executed using the tripod legs instead of the tribrach. In return, the PCV and the near-field effects can be corrected later in the processing, while far-field multipath will cancel out with sufficiently long 
observation time.

The used GPS field equipment and setup consists of Trimble 4700 receivers and Ashtech Dorne Margolin chokering antennas. The pre-defined tribrach/tripod geometry was used for the field stations enabling the optimized correction of PCV and near-field. At the five benchmarks, $48 \mathrm{~h}$ of GPS data with a data rate of $10 \mathrm{~s}$ were collected. Although the largest gross error source in GNSS is still the antenna height measurement, only one station setup was conducted, but the antenna heights were determined several times by means of spirit leveling. In addition to the five field stations on the traverse, data of six surrounding permanent reference stations (five SAPOS stations) was collected to enable and analyze absolute positioning. The distances between the field stations is approximately 1 to $2 \mathrm{~km}$ (Figure 2), while the distances to the reference stations are between 10 and $39 \mathrm{~km}$. All reference station antennas were individually calibrated.

The estimation of the troposphere depends on the one hand on proper separation of antenna and near-field impact from the actual GPS observations and on the other hand on sophisticated tropospheric modeling. The correction of PCV and near-field is pre-requisite to avoid any mismodeling of delays not caused by the troposphere. The high correlation of station dependent errors and tropospheric delays can significantly degrade height accuracy. Very small antenna PCV changes are amplified in the tropospheric models and transfer into height errors of much larger size (Wübbena et al. 2006).

The Geo++ GNSMART software with the core module GNNET is used for the GPS data processing. Several processing strategies with different tropospheric modeling and antenna corrections were applied. The models are generally implemented as stochastic processes (e.g., depending on time, elevation, spatial distance). A multi stage approach is used for the troposphere: larger spatial correlation of the troposphere are estimated by area polynomials and additionally station dependent models in combination with local tropospheric models are applied. In all cases the Niell tropospheric model (Niell 1996) is initially used.

The corrections estimated in the tropospheric model are valid for the zenith. A mapping function is required to compute the tropospheric delay for any given satellite elevation. The accuracy of the tropospheric model for low elevations is especially critical. Improvement of tropospheric modeling often focus on the mapping functions, but it is difficult to find one single mapping function ideally suited for any regional tropospheric characteristics. Therefore a different approach is implemented in GNNET, which uses the default Niell mapping function, but adaptively improves the function for elevation below 18 deg using the actual observation data.

The station dependent characteristics of the tropospheric modeling is considered by a scale factor in the adjustment. The stochastic process in time precisely models any temporal changes and distinguishes between the dry and wet component. Despite the divisive variety of modeling options, there are in practice often remaining tropospheric residuals due to insufficiently complete modeling. To absorb additional effects a so-called tropospheric gradient is used (Rothacher et al. 1998). The term tropospheric gradient is misleading, because it is a simple tilt of the applied local troposphere model. The gradient model is not a physical model to follow the actual troposphere, but an approximate approach that generally yields model improvements. 
Local tropospheric effects are more complex than a simple and pure geometric model can describe. Therefore a completely elevation- and azimuth-dependent model using spherical harmonics is applied alternatively in an extended (azimuthal) model, which can absorb such effects. The separation from other errors, however, becomes more difficult and critical in this case. Prerequisite for such models is, that the antenna phase variations are precisely corrected and near-field multipath effects are analyzed and to the best extent avoided or corrected beforehand.

Table 3 summarizes the basic models applied in the different GPS processing variants. For all variants a simultaneous L1 and L2 estimation in combination with an ionospheric model and precise ephemeris was used for all field and permanent reference stations. The elevation cut-off is $5^{\circ}$ to support optimum tropospheric modeling. The GNNET adaptive improvement of the mapping function with the Niell tropospheric model was always applied. Therefore no or only minor impact from the chosen tropospheric model is expected and no other models (e.g., the Vienna mapping functions, Boehm et al. 2006a, 2006b) were investigated. The main differences are in the modeling of local tropospheric delays using: solely a scaling factors, additional tropospheric gradients, or an extended model based on spherical harmonics. The antenna corrections differ between individual, absolute PCV calibrations or a near-field type calibration.

\section{Comparisons and analyses}

Between the five benchmarks, ellipsoidal height differences $\Delta h$ were computed evaluating the basic equation of geometric-astronomical leveling (10) with the leveled height increments $\Delta n$ (11) and the vertical deflections $\varepsilon$ (12). Because the path of the geometric leveling did not coincide with the vertical deflection traverse (see explanations given in Sec. 4), the orthometric correction does not cancel out here. Test computations using predicted gravity data showed that the correction terms $E_{A B}^{O}(3)$ are very small (order of 0.1-0.2 mm) and, hence, do not play a significant role in this study.

Taking into account firstly the effect of the orthometric correction, secondly the uncertainties of leveled height differences $\Delta H_{i j}^{*}$ between adjacent stations (0.8-1.7 mm, cf. Sec. 4.1) and, thirdly those of the geoid undulations $\Delta N_{i j}^{*}$ (a few $0.2 \mathrm{~mm}$, cf. Sec. 4.2), we conclude that the ellipsoidal height differences $\Delta h$ from geometric-astronomical leveling are accurate to 1-2 mm (Eq. 13). Although less accurate than theoretically possible (cf. Sec. 3), these height differences can be used for (mutual) validation of our GNSS height measurements and for evaluation of the GNSS processing strategies.

The comparison among ellipsoidal height differences $\Delta h_{G A L}$ from the geometric-astronomical leveling and the height differences $\Delta h_{G P S}$ from GPS (Sec. 4.3) yielded residual differences 


$$
\delta \Delta h=\Delta h_{G A L}-\Delta h_{G P S} .
$$

These are compiled for five different GPS-processing variants and for the adjacent pairs of benchmarks $\mathrm{AB}, \mathrm{BC}, \mathrm{CD}$ and $\mathrm{DE}$ in Table 4 . The residuals generally do not exceed $5 \mathrm{~mm}$, as such indicating a good agreement between the height differences from both methods in our test area. The mean values, computed from the differences, are found to vary between $0.9 \mathrm{~mm}$ and $1.4 \mathrm{~mm}$ while the RMS values range between $3.7 \mathrm{~mm}$ and $2.3 \mathrm{~mm}$. In fact, the residuals reflect all uncertainties originating from geometric-astronomical leveling and those from the GPS height differences. Clearly, this is a manifestation that GPS is capable of attaining an accuracy level of a few millimeter for ellipsoidal height differences over short distances.

Schmitz and Wübbena (2007) performed a comparison of the GPS height measurements with geometric leveling and (quasi)geoid undulations from the German Combined Quasigeoid 2005 (GCG05, cf. Schirmer et al. 2006), i.e. the quasigeoid height differences from GCG were introduced in (10) instead of astrogeodetic undulations from vertical deflections. The RMS residuals range between $2.1 \mathrm{~mm}$ and $3.7 \mathrm{~mm}$. However, the mean differences (listed in Table 5) are found to be $0.5 \mathrm{~mm}$ and below which is even smaller than those in Table 4. This indicates a very good quality of the model GCG05 in our test area. What is more, the comparison using GCG05 independently confirms the improvement related to the near-field calibration.

A closer look at the RMS errors allows evaluation of the GPS processing concepts which were characterized in Table 3. The chosen methodology in the comparison using coordinates differences eliminates or greatly reduces any impact from the reference stations. The different processing strategies verify the expectations discussed in the GNSS observation and processing section (Sec. 4.3). There is a maximum improvement in RMS from $3.7 \mathrm{~mm}$ to about $2.3 \mathrm{~mm}$ for the height component using the antenna corrections from the near-field calibration (variants 07/08 vs. variants 09/10). An additional GPS improvement is achieved with the extended tropospheric model. Although the RMS is slightly higher than for the standard modeling or the model with tropospheric gradient, the mean height difference is smaller (Table 5). Likewise, the comparison with the geometric-astronomical leveling (Table 4) gives some indication that the near-field correction (variants 09/10) as well as the gradient model (variants 08/09) improves the height determination.

The comparisons indicate that all three involved measurement techniques perform within the data set at a similar precision level. Only one method is varied in an independent way, which is the geoid computation. The geometric leveling is always the same, while the GPS processing varies only in the modeling options. Depending on the comparison also the conclusion from the validation of the GNSS height measurements slightly differ. However, this underlines the need for further efforts in validating the methods against each other, but also clearly demonstrates the $1 \mathrm{~mm}$ potential of GNSS height determination. Analysis of absolute GNSS height determination using these stations is not subject of our study.

\section{Conclusions}

In this study we have described and tested the method of geometric-astronomical leveling for 
validation of GPS height measurements. Geometric-astronomical leveling delivers accurate ellipsoidal height differences from the combination of spirit leveling and astronomical leveling. Due to the availability of DZCS, the latter technique is increasingly applied for very accurate local gravity field determination in general and enables accurate geometric-astronomical determination of ellipsoidal height differences in particular.

A field experiment was carried out in a test area in Northern Germany where a dense set of accurate vertical deflection data was available from DZCS observations $(50 \mathrm{~m}$ spatial resolution). Geometric leveling and sophisticated GPS observations were performed between five benchmarks. It was concluded that the ellipsoidal height differences between adjacent benchmarks, as obtained from geometric-astronomical leveling, are accurate to about 1-2 mm, allowing here a mutual validation with GPS height measurements. The comparison with GPS derived height differences showed a good agreement with residuals at the level of few millimeter. As important result, it turned out that the residuals are lowest for the processing variants with the antenna corrections from the near-field calibration applied. Both the RMS values from differences and the mean differences provide some evidence of the $1 \mathrm{~mm}$ accuracy potential for GPS heighting.

Our results demonstrate for the first time the capability of geometric-astronomical leveling for GPS height validation and the evaluation of GPS height processing strategies. These tasks are of considerable relevance in the context of precise GNSS leveling as economical substitute of geometric leveling. This holds especially true with respect to the modernization of the national first order height networks, such as the German DHHN (Deutsches Haupthöhennetz), where GNSS heighting plays a fundamental role (Feldmann-Westendorff 2009; AdV 2007).

The authors fully acknowledge that there is some clear need for improvement in future application of geometric-astronomical leveling. First, other than in this study, the location of a future test area should be chosen well aside from potential sources of refractivity, such as landwater transitions. That way refractional influences on the vertical deflection measurements, and, hence, on the resulting geoidal height differences can be reduced. Second, the same path of integration is required for both geometrical and astronomical leveling. Third, a spatial resolution of the deflection data of some $100 \mathrm{~m}$ is certainly sufficient, enhancing the efficiency of astronomical leveling. In rugged terrain, interpolation of the vertical deflections can be done by means of digital terrain model data. Taking these issues into account, the error sources of geometric-astronomical leveling can be kept reasonably small and an accuracy level of 0.5 - 0.6

$\mathrm{mm} / \sqrt{\mathrm{km}}$ for ellipsoidal height differences is to be expected in geodetic field experiments. This could promote further application of the proposed approach for validation of GNSS height measurements and assessment of GNSS processing models.

\section{Acknowledgement}

Parts of the field observations were supported by German National Research Foundation (DFG) under grant number Se 313/22. 


\section{References}

AdV (2007) Feldanweisung für die GNSS-Messungen zur Erneuerung und Wiederholung des Deutschen Haupthöhennetz DHHN im Zeitraum 2006 bis 2011. Arbeitsgemeinschaft der Vermessungsverwaltungen der Länder der Bundesrepublik Deutschland (AdV-Arbeitskreis Raumbezug)

Bäumker M (1984) Zur dreidimensionalen Ausgleichung von terrestrischen und Satellitenbeobachtungen. Wiss. Arb. Fachr. Verm.wesen der Univ. Hannover Nr. 130

Boehm J, Werl B, Schuh H (2006a), Troposphere mapping functions for GPS and very long baseline interferometry from European Centre for Medium-Range Weather Forecasts operational analysis data. J Geophys. Res., 111: B02406. DOI:10.1029/2005JB003629

Boehm J, Niell AE, Tregoning P, Schuh H (2006b) Global Mapping Function (GMF): A new empirical mapping function based on numerical weather model data. Geoph. Res. Letters, 33: L07304. DOI:10.1029/2005GL025546

Bomford G (1980) Geodesy, Fourth Edition. Clarendon Press, Oxford

Dilßner F, Seeber G, Wübbena G, Schmitz M (2008) Impact of near-field effects on the GNSS Position Solution. International Technical Meeting ION GNSS-08, Savannah, Georgia

Elosegui P, Davis JL, Jaldehag RK, Johansson JM, Niell AE, Shapiro II (1995) Geodesy using the Global Positioning System: The effects of signal scattering on estimates of site position. J Geophys Res 100(B6):9921-9934

Featherstone WE, and Kuhn M (2006) Height systems and vertical datums: a review in the Australian context. Journal of Spatial Science 51(1):21-42

Featherstone WE (2008) GNSS-based heighting in Australia: Current, emerging and future issues. Journal of Spatial Science 53(2):115-133

Feldmann-Westendorff U, Jahn C-H (2006) GNSS-Höhenbestimmung in einem einheitlichen Raumbezug. 66. DVW-Seminar "GPS und GALILEO", Deutscher Verein für Vermessungswesen e. V. - Gesellschaft für Geodäsie, Geoinformation und Landmanagement, 21.-22.02.2006, Darmstadt, Schriftenreihe 49/2006:147-171

Feldmann-Westendorff U (2009) Von der See bis zu den Alpen: Die GNSS-Kampagne 2008 im DHHN 2006-2011. 83. DVW Seminar "GNSS 2009: Systeme, Dienste und Anwendungen", Deutscher Verein für Vermessungswesen e. V. - Gesellschaft für Geodäsie, Geoinformation und Landmanagement, 18.- 19.03.2009, Dresden, Schriftenreihe 57/2009:95-112

Helmert FR (1880/1884) Die mathematischen und physikalischen Theorien der höheren Geodäsie. Teubner, Leibzig (reprint Minerva, Frankfurt a.M. 1961)

Heiskanen WA, Moritz H (1967) Physical Geodesy. W.H. Freeman and Company, San Francisco

Heitz S (1973) Ein dreidimensionales Berechnungsmodell für Punktbestimmungen mit Berücksichtigung orthometrischer Höhen. Zeitschrift f. Vermessungswesen 98(11):479485 
Hirt C (2006) Monitoring and analysis of anomalous refraction using a Digital Zenith Camera System. Astronomy and Astrophysics 459:283-290. DOI: 10.1051/0004-6361:20065485

Hirt C, Seeber G (2007) High-Resolution local gravity field determination at the sub-millimeter level using a Digital Zenith Camera System. Dynamic Planet, Cairns 2005 (ed. P. Tregoning and C. Rizos), IAG Symposia 130:316-321

Hirt C, Denker H, Flury J, Lindau A, Seeber G (2007) Astrogeodetic validation of gravimetric quasigeoid models in the German Alps - first results. Proceed. 1. Intern. Symp. of the International Gravity Field Service, Istanbul, Turkey, Harita Dergisi, Special Issue 18:8489

Hirt C, Flury J (2008) Astronomical-topographic leveling using high-precision astrogeodetic vertical deflections and digital terrain model data. J Geod 82(4-5):231-248

Hirt C, Seeber G (2008) Accuracy analysis of vertical deflection data observed with the Hannover Digital Zenith Camera System TZK2-D. J Geod 82(6):347-356

Hirt C, Feldmann-Westendorff, U, Denker H, Flury J, Jahn C-H, Lindau A, Seeber G, Voigt C (2008). Hochpräzise Bestimmung eines astrogeodätischen Quasigeoidprofils im Harz für die Validierung des Quasigeoidmodells GCG05. Zeitschrift f. Vermessungswesen 133(2):108-1 19

Hirt C (2009) Hochauflösende astrogeodätische Bestimmung von Geoid- und Äquipotentialprofilen für die Vermessung von Teilchenbeschleunigern. Allgemeine Vermessungsnachrichten 2009(2):48-63

Hirt C, Bürki B, Somieski A, Seeber G (2010) Modern determination of vertical deflections using digital zenith cameras. J. Surv. Eng. 136(1):1-12

Jekeli C (1999) An analysis of vertical deflections derived from high-degree spherical harmonic models. J Geod 73(1):10-22. DOI: 10.1007/s00 1900050213

Meyer TH, Roman DR, Zilkoski DB (2006a) What does height really mean? Part IV: GPS Heighting. Surveying and Land Information Science 66(3):165-183

Meyer TH, Roman DR, Zilkoski DB (2006b) What does height really mean? Part III: Height Systems. Surveying and Land Information Science, 66(2):149-160

Mogilevsky E, Melzer Y (1994) Determining deflection of the vertical with GPS. Proceedings ION GPS-94:371-374

Molodenski MS, Eremeev VF, Yurkina MI (1962) Methods for study of the External Gravitational Field and Figure of the Earth. Transl. from Russian (1960). Israel Program for Scientific Translations Ltd, Jerusalem

Niell AE (1996) Global Mapping Functions for the Atmosphere Delay at Radio Wavelength. Journal of Geophysical Research 101(B2):3227-3246

Ruland R, Leick A (1985) Application of GPS to a High Precision Engineering Survey Network. Proceedings of Positioning with GPS-1985, 483-493, National Geodetic Survey

Rothacher M, Springer TA, Schaer S, Beutler G (1998) Processing Strategies for Regional GPS networks. IAG Symposia 118:93-101

Schirmer U., Denker H., Ihde J., Liebsch G. und Müller J. (2006) A new combined height 
reference surface for Germany (GCG05). Symposium of the IAG Subcommission for Europe (EUREF), Riga, 2006

Schmitz M, Wübbena G (2007) Einflüsse auf die GNSS Höhenbestimmung - Grenzen und Chancen -. 5. ascos Anwender- und Kundentreffen, e•on, Ruhrgas; 10. und 11. Mai 2007, Akademie Mont-Cenis, Herne

Seeber G (2003) Satellite Geodesy. Second edition, de Gruyter, Berlin, New York

Soler T, Carlson AE, Evans AG (1989) Determination of Vertical Deflections using the Global Positioning System and Geodetic leveling. Geophys Res Let 16(7):695-698

Torge W, Boedecker G, Wenzel H-G (1975) Astrogeodetic Geoid Determination in the Western Harz. Proceedings XVI General Assembly IUGG/IAG, Grenoble 1975

Torge W (1977) Höhen- und Geoidbestimmung im dreidimensionalen Testnetz Westharz. Zeitschrift f. Vermessungswesen 102(4):173-185

Torge W, Wenzel H-G (1978) Dreidimensionale Ausgleichung des Testnetzes Westharz. Deutsche Geodätische Kommission B 234, Munich

Torge W (2001) Geodesy, Third Edition. W. de Gruyter, Berlin, New York

Tse CM, Baki Iz H (2006) Deflection of the Vertical Components from GPS and Precise leveling Measurements in Hong Kong. J. Surv. Eng. 132(3):97-100

Vaníček P, Castle RO, Balazs EI (1980) Geodetic leveling and its applications. Reviews of Geophysics and Space Physics 18(2):502-524

Wübbena G, Schmitz M, Menge F, Böder V, Seeber G (2000) Automated Absolute Field Calibration of GPS Antennas in Real-Time. Presented at ION GPS-00, 19-22 September, Salt Lake City, Utah, USA

Wübbena G, Schmitz M, Boettcher G (2003) Zum Einfluss des Antennennahfeldes. 5. GPSAntennen-Workshop 2003 (ed. B. Görres, J. Campbell, G. Seeber) Geodätisches Institut der Universität Bonn und Institut für Erdmessung der Universität Hannover, im Rahmen des 5. SAPOS-Symposiums. 3. November 2003, Frankfurt/Main, Germany

Wübbena G, Schmitz M, Boettcher G (2006) Near-field Effects on GNSS Sites: Analysis using Absolute Robot Calibrations and Procedures to Determine Corrections. Paper presented at IGS Workshop 2006 Perspectives and Visions for 2010 and beyond, May 8-12, ESOC, Darmstadt, Germany 


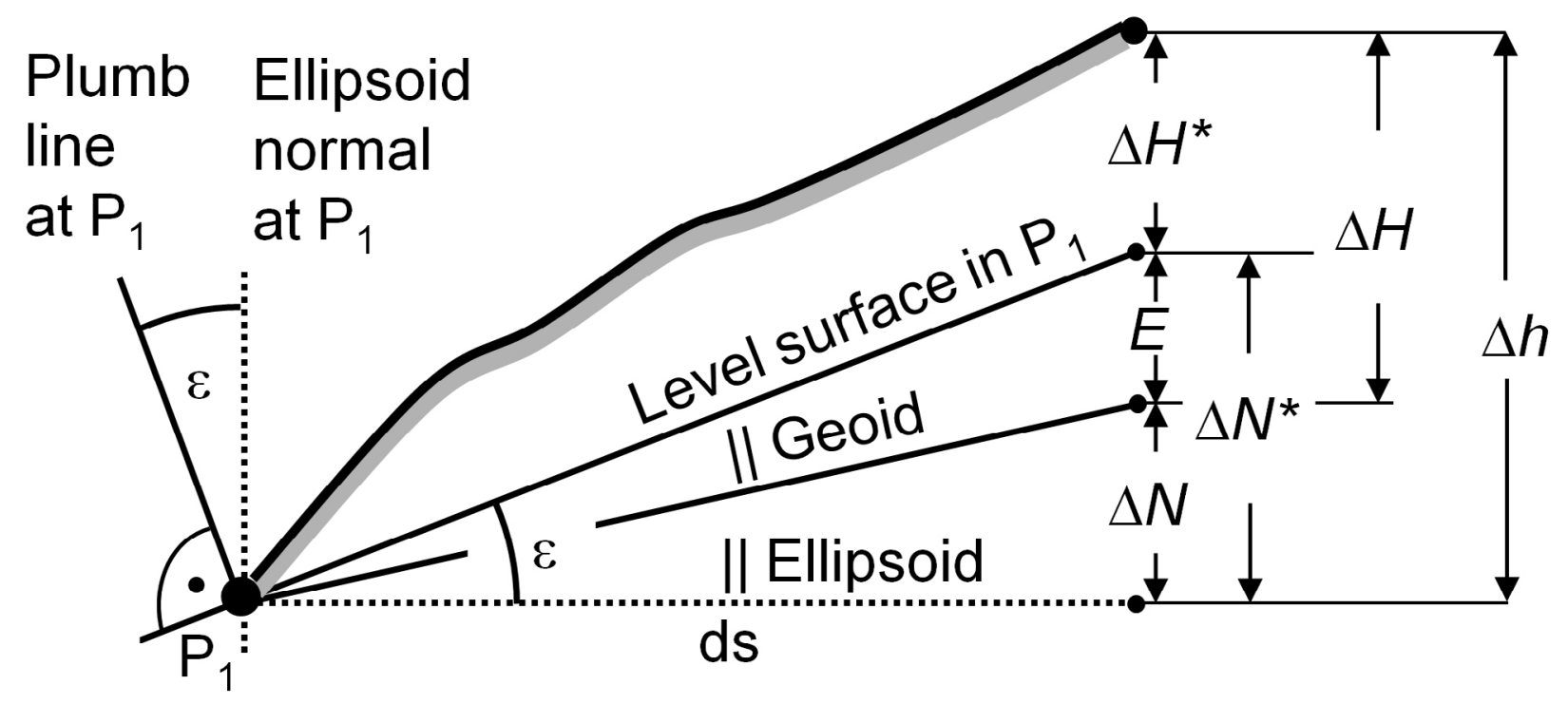

Fig 1 Principle of geometric-astronomical leveling. $\Delta h$ ellipsoidal height difference between adjacent stations, $\Delta H$ orthometric height difference, $\Delta N$ geoidal height difference, $E$ orthometric correction, $\Delta H^{*}$ sum of raw height increments, $\Delta N^{*}$ geoidal height difference without orthometric correction, $d s$ station spacing, $\varepsilon$ vertical deflection.

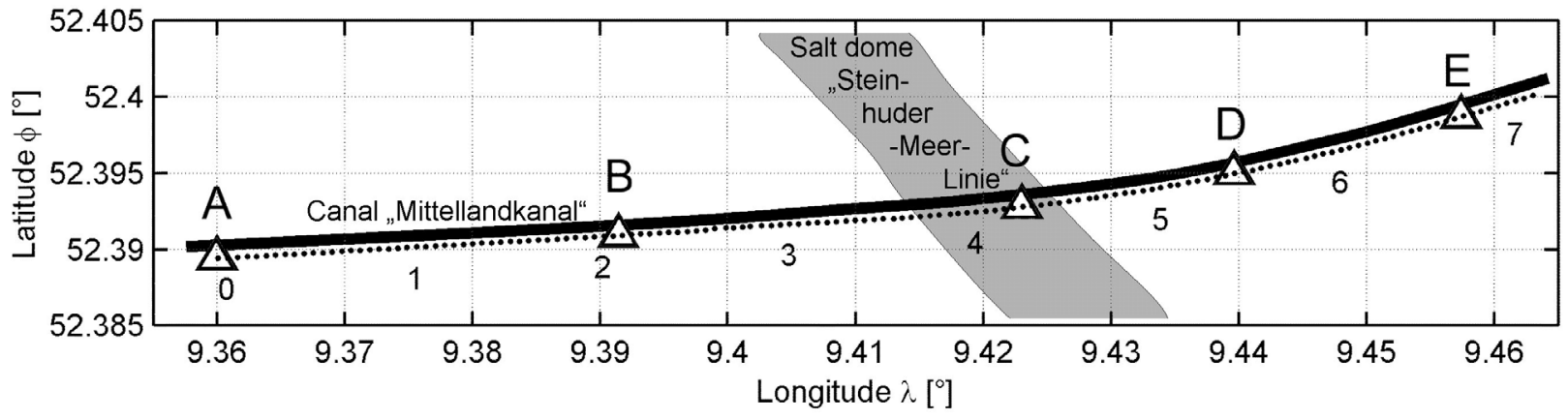

Fig 2 Test area and station arrangement. Small dots: vertical deflections stations, Triangles A-E: Benchmarks with GPS observations, astrogeodetic geoid undulations and spirit-leveled heights. Numbers 0-7 indicate the distances in $\mathrm{km}$ with respect to station A. 


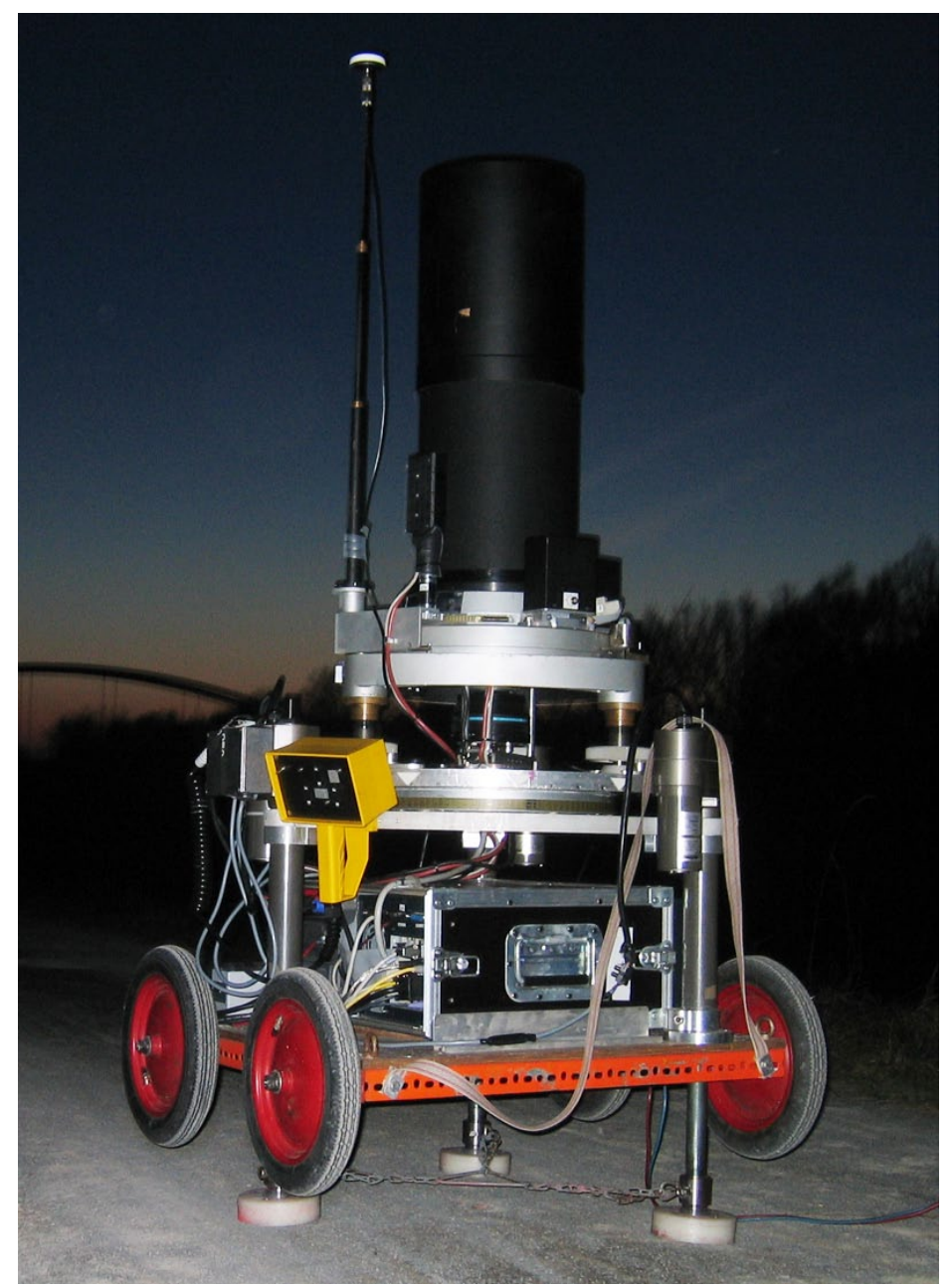

Fig 3 Digital Zenith Camera System TZK2-D (University of Hanover) in use for vertical deflection measurements along the "Mittellandkanal" 

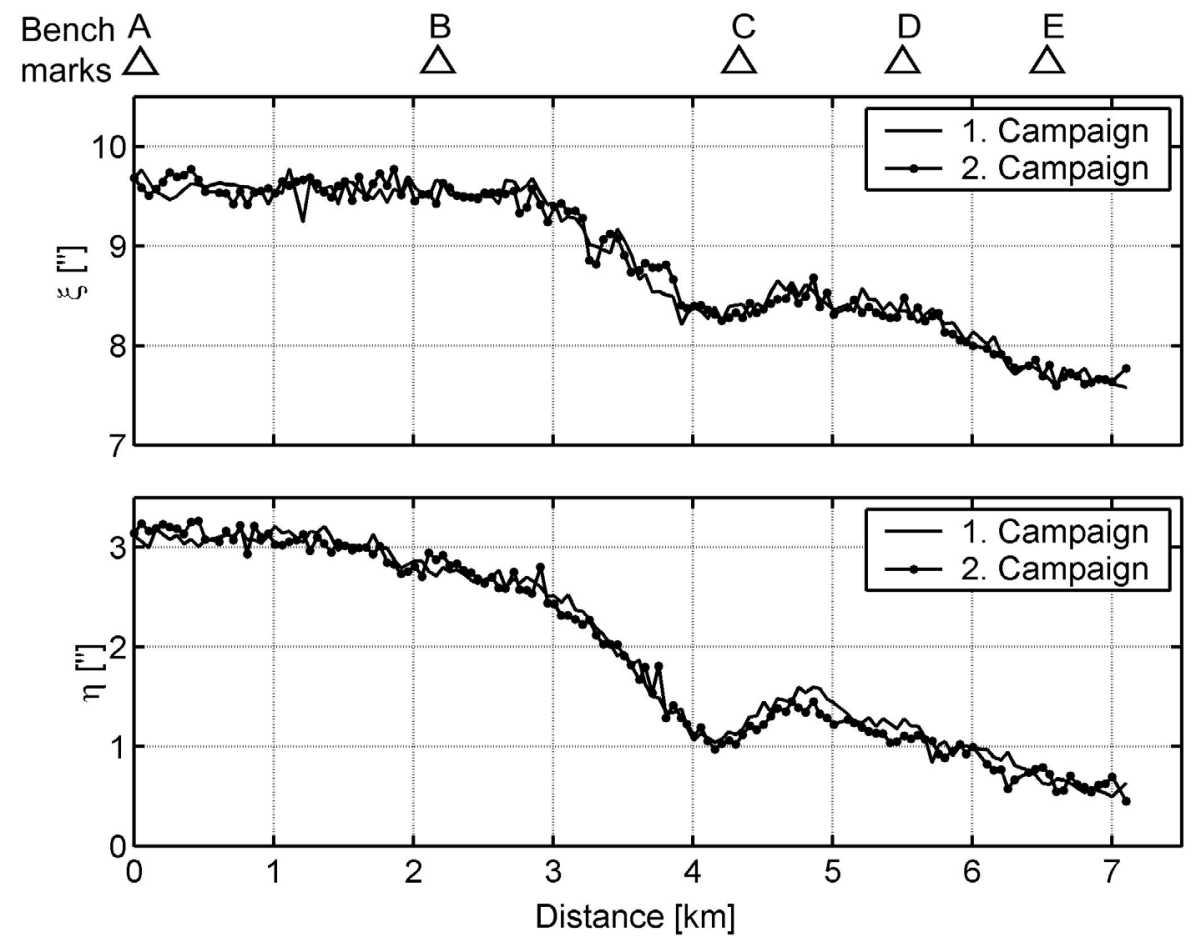

Fig 4 Vertical deflections $(\xi, \eta)$ along the traverse. Top: component $\xi$. Bottom: component $\eta$. 1. (2.) Campaign refers to the observations in spring 2005 (autumn 2005). It should be noted that the vertical deflection data around benchmark $\mathrm{C}$ features a wave-like structure, originating from the gravitational impact of the salt dome.

Table 1 Standard deviations of levelled height differences $\sigma_{\Delta H}$ from least-squares adjustment

\begin{tabular}{|c|c|c|c|}
\hline Stations & $\sigma_{\Delta H}$ [mm] & $\begin{array}{c}\text { Levelling } \\
\text { run [m] }\end{array}$ & $\begin{array}{c}\text { Shortest } \\
\text { distance [m] }\end{array}$ \\
\hline A-B & 1.7 & 6422 & 2153 \\
\hline B-C & 1.3 & 3552 & 2155 \\
\hline C-D & 1.2 & 2830 & 1157 \\
\hline D-E & 0.8 & 1397 & 1286 \\
\hline
\end{tabular}

Table 2 Residuals of geoid undulation height differences, as obtained from repeated vertical deflection observations in spring 2005 and autumn 2005

\begin{tabular}{|c|c|c|}
\hline Stations & $\begin{array}{c}\text { Distance } \\
\text { [m] }\end{array}$ & $\begin{array}{c}\Delta N^{*} \text { (spring) }-\Delta N^{*} \text { (autumn) } \\
\text { [mm] }\end{array}$ \\
\hline A-B & 2153 & +0.01 \\
\hline B-C & 2155 & -0.09 \\
\hline C-D & 1157 & -0.71 \\
\hline D-E & 1286 & -0.29 \\
\hline
\end{tabular}


Table 3 Antenna corrections and tropospheric modeling of the GNNET processing. In column 'extended', the numbers indicate the degree and order of the spherical harmonic model used.

\begin{tabular}{|c|c|c|c|c|}
\hline Variant & $\begin{array}{c}\text { Antenna } \\
\text { correction }\end{array}$ & \multicolumn{3}{|c|}{ Tropospheric modeling (Niell) } \\
\hline & & & \multicolumn{2}{c|}{ local tropospheric model } \\
\hline & & $\begin{array}{c}\text { scale } \\
\text { dry+wet }\end{array}$ & gradient & extended \\
\hline 07 & individual PCV & $\mathrm{x}$ & - & - \\
\hline 08 & individual PCV & $\mathrm{x}$ & $\mathrm{x}$ & - \\
\hline 09 & type NF+PCV & $\mathrm{x}$ & $\mathrm{x}$ & - \\
\hline 10 & type NF+PCV & $\mathrm{x}$ & - & - \\
\hline 13 & type NF+PCV & $\mathrm{x}$ & - & $(5,4)$ \\
\hline
\end{tabular}

Table 4 Differences $\delta \Delta h$ in [mm], as obtained between geometric-astronomical leveling and different GPS processing variants.

\begin{tabular}{|c|c|c|c|c|c|c|}
\hline Stations & $\begin{array}{c}\text { Distance } \\
{[\mathbf{m}]}\end{array}$ & \multicolumn{2}{|c|}{$\begin{array}{c}\text { individual PCV } \\
\text { corrected }\end{array}$} & \multicolumn{3}{c|}{ type near field + PCV corrected } \\
\hline & & Variant 07 & Variant 08 & Variant 09 & Variant 10 & Variant 13 \\
\hline A-B & 2153 & -0.9 & -2.5 & -2.9 & -1.1 & 0.4 \\
\hline B-C & 2155 & -4.6 & -2.3 & -1.4 & -3.1 & -4.1 \\
\hline C-D & 1157 & 4.2 & 3.8 & 2.0 & 1.5 & 2.2 \\
\hline D-E & 1286 & -3.8 & -3.4 & -2.9 & -2.8 & -2.2 \\
\hline RMS & & 3.7 & 3.1 & 2.4 & 2.3 & 2.6 \\
\hline mean & & -1.3 & -1.1 & -1.3 & -1.4 & -0.9 \\
\hline
\end{tabular}

Table 5 Differences $\delta \Delta h$ in [mm], as obtained between geometric leveling/German Combined Geoid (GCG05) and different GPS processing variants.

\begin{tabular}{|c|c|c|c|c|c|c|}
\hline Stations & $\begin{array}{c}\text { Distance } \\
{[\mathbf{m}]}\end{array}$ & \multicolumn{2}{|c|}{$\begin{array}{c}\text { Individual PCV } \\
\text { corrected }\end{array}$} & \multicolumn{3}{c|}{ type near field + PCV corrected } \\
\hline & & Variant 07 & Variant 08 & Variant 09 & Variant 10 & Variant 13 \\
\hline A-B & 2153 & 0.6 & -1.0 & -1.4 & 0.4 & 1.9 \\
\hline B-C & 2155 & -3.9 & -1.6 & -0.7 & -2.4 & -3.4 \\
\hline C-D & 1157 & 5.2 & 4.8 & 3.0 & 2.5 & 3.2 \\
\hline D-E & 1286 & -3.5 & -3.1 & -2.6 & -2.5 & -1.9 \\
\hline RMS & & 3.7 & 3.0 & 2.1 & 2.1 & 2.7 \\
\hline mean & & -0.4 & -0.2 & -0.4 & -0.5 & -0.0 \\
\hline
\end{tabular}

